\title{
Enthalpy of solvation of butanediols in different solvents
}

\author{
A.J. Lopes Jesus, M. Ermelinda Eusébio, J.S. Redinha, M.L.P. Leitão* \\ Departamento de Química, Universidade de Coimbra, 3000 Coimbra, Portugal
}

Accepted 23 August 1999

\begin{abstract}
The enthalpies of solution for 1,2-, 1,3-, 1,4- and 2,3-butanediol in water, formamide and dimethylsulphoxide were determined by calorimetry. From the results and data available in the literature for the enthalpy of vaporisation, the enthalpy of solvation was determined. The enthalpy of solvation was decomposed into two terms, cavity formation in the solvent to hold the solute and solute-solvent interaction. (C) 2000 Elsevier Science B.V. All rights reserved.
\end{abstract}

Keywords: Solvation enthalpy; Alkanediols; Non-electrolyte solutions; Solute-solute interactions; Hydrophobic hydration

\section{Introduction}

The present paper intends to be a contribution to the understanding of the behaviour of polyols towards polar solvents in particular towards water. This is an important scientific topic because polyols, as well as polyfunctional compounds in general, are part of systems of biological interest. The interaction of this type of solutes with water as well as the interaction of the solute molecules between themselves play a key role in the interpretation of many biological processes.

Butanediols form a group of compounds which allow the investigation of many aspects arising in polyol solutions. In fact, they are relatively simple molecules, the molecular backbone gives rise to different conformations, both polar and non-polar moieties are significant, the distance between the polar groups varies from one positional isomer to the other

\footnotetext{
* Corresponding author. Fax: +351-39-827703.

E-mail address: mlleitao@cygnus.ci.uc.pt (M.L.P. Leitão).
}

and internal hydrogen bonds of different strength are possible [1-4].

In this work butanediol positional isomers were used as solutes and water (W), formamide (FMD) and dimethylsulphoxide (DMSO) were used as solvents. Enthalpy of solution is the property used in this study.

The role of the polar solvents can be understood when studies involving various solvent media are also considered. In particular the behaviour of water can be evidenced by comparing the results obtained for the three liquids used.

From the enthalpy of solution, the enthalpy of solvation was determined for those isomers which have values quoted in the literature for the enthalpy of vaporisation.

To estimate the enthalpy due to solute-solvent interactions from the enthalpy of solvation, the enthalpy for the formation of a cavity in a solvent was calculated using scaled particle theory (SPT) $[5,6]$. 
Table 1

Enthalpies of solution of isomeric butanediols in different solvents at $298.15 \mathrm{~K}$

\begin{tabular}{|c|c|c|c|c|c|}
\hline \multicolumn{2}{|c|}{ 1,2-Butanediol/W } & \multicolumn{2}{|c|}{ 1,2-Butanediol/FMD } & \multicolumn{2}{|c|}{ 1,2-Butanediol/DMSO } \\
\hline$m\left(\mathrm{~mol} \mathrm{~kg}^{-1}\right)$ & $\Delta_{\mathrm{sol}} H\left(\mathrm{~kJ} \mathrm{~mol}^{-1}\right)$ & $m\left(\mathrm{~mol} \mathrm{~kg}^{-1}\right)$ & $\Delta_{\mathrm{sol}} H\left(\mathrm{~kJ} \mathrm{~mol}^{-1}\right)$ & $m\left(\mathrm{~mol} \mathrm{~kg}^{-1}\right)$ & $\Delta_{\mathrm{sol}} H\left(\mathrm{~kJ} \mathrm{~mol}^{-1}\right)$ \\
\hline 0.0447 & -11.733 & 0.1166 & 0.834 & 0.1107 & -1.543 \\
\hline 0.0820 & -11.582 & 0.1616 & 0.807 & 0.1360 & -1.458 \\
\hline 0.1072 & -11.584 & 0.1851 & 0.845 & 0.1590 & -1.457 \\
\hline 0.1624 & -11.566 & 0.2303 & 0.823 & 0.1924 & -1.334 \\
\hline 0.1808 & -11.566 & 0.2461 & 0.856 & 0.2116 & -1.304 \\
\hline 0.2316 & -11.532 & 0.2784 & 0.841 & 0.2452 & -1.355 \\
\hline 0.2700 & -11.507 & 0.3283 & 0.834 & 0.3369 & -1.316 \\
\hline \multirow[t]{3}{*}{0.2774} & -11.444 & 0.3788 & 0.890 & & \\
\hline & & 0.4298 & 0.858 & & \\
\hline & & 0.4606 & 0.866 & & \\
\hline
\end{tabular}

\section{Experimental}

High grade isomeric butanediols, purity $>99 \%$, were used without further purification. FMD and DMSO were the best grade available, water content $\leq 0.03 \%$ for the former and $\leq 0.01 \%$ for the latter. High purity water delivered by a Millipore purifier unity was used. All organic compounds were handled in a dry box in order to avoid contamination with water from atmosphere. Apparatus and techniques used in the determination of the enthalpy of solution were described previously [7].

\section{Results}

The results obtained for the enthalpy of solution are given in Tables 1-4. From the variation of $\Delta_{\text {sol }} H$ with concentration the limiting value at infinite dilution, $\Delta_{\text {sol }} H^{0}$ was determined. The only comparison of our results with those available in the literature for the systems under study is for the enthalpy of solution of 1,4-butanediol in water. Nichols et al. [8] found a value $0.2 \mathrm{~kJ} \mathrm{~mol}^{-1}$ higher than that obtained in the present work.

The enthalpy of solvation was obtained from the enthalpies of solution and vaporisation

$$
\Delta_{\text {solv }} H^{0}=\Delta_{\text {sol }} H^{0}-\Delta_{\text {vap }} H^{0} .
$$

The value taken for $\Delta_{\mathrm{vap}} H^{0}$, expressed in $\mathrm{kJ} \mathrm{mol}^{-1}$ are the following: 1,2-butanediol [9] $=71.55,1$,3-butanediol [9] $=74.46,1,4$-butanediol [10] $=79.3$. No reliable data are found for $\Delta_{\mathrm{vap}} H^{0}$ of 2,3-butanediol in the literature.

Table 2

Enthalpies of solution of isomeric butanediols in different solvents at $298.15 \mathrm{~K}$

\begin{tabular}{|c|c|c|c|c|c|}
\hline \multicolumn{2}{|c|}{ 1,3-Butanediol/W } & \multicolumn{2}{|c|}{ 1,3-Butanediol/FMD } & \multicolumn{2}{|c|}{ 1,3-Butanediol/DMSO } \\
\hline$m\left(\mathrm{~mol} \mathrm{~kg}^{-1}\right)$ & $\Delta_{\mathrm{sol}} H\left(\mathrm{~kJ} \mathrm{~mol}^{-1}\right)$ & $m\left(\mathrm{~mol} \mathrm{~kg}{ }^{-1}\right)$ & $\Delta_{\mathrm{sol}} H\left(\mathrm{~kJ} \mathrm{~mol}^{-1}\right)$ & $m\left(\mathrm{~mol} \mathrm{~kg}^{-1}\right)$ & $\Delta_{\mathrm{sol}} H\left(\mathrm{~kJ} \mathrm{~mol}^{-1}\right)$ \\
\hline 0.0316 & -11.807 & 0.0975 & 3.094 & 0.1632 & -0.083 \\
\hline 0.0460 & -11.868 & 0.1699 & 3.218 & 0.1700 & -0.077 \\
\hline 0.0961 & -11.836 & 0.1716 & 3.213 & 0.1909 & -0.074 \\
\hline 0.1341 & -11.850 & 0.2227 & 3.248 & 0.1936 & -0.075 \\
\hline 0.1914 & -11.721 & 0.2452 & 3.275 & 0.2167 & -0.073 \\
\hline 0.2259 & -11.695 & 0.2711 & 3.322 & 0.2816 & -0.077 \\
\hline 0.2751 & -11.709 & 0.2839 & 3.262 & 0.2961 & -0.068 \\
\hline \multirow[t]{4}{*}{0.2785} & -11.616 & 0.2921 & 3.297 & 0.4052 & -0.063 \\
\hline & & 0.3203 & 3.271 & & \\
\hline & & 0.3497 & 3.296 & & \\
\hline & & 0.3647 & 3.311 & & \\
\hline
\end{tabular}


Table 3

Enthalpies of solution of isomeric butanediols in different solvents at $298.15 \mathrm{~K}$

\begin{tabular}{|c|c|c|c|c|c|}
\hline \multicolumn{2}{|c|}{ 1,4-Butanediol/W } & \multicolumn{2}{|c|}{ 1,4-Butanediol/FMD } & \multicolumn{2}{|c|}{ 1,4-Butanediol/DMSO } \\
\hline$m\left(\mathrm{~mol} \mathrm{~kg}^{-1}\right)$ & $\Delta_{\mathrm{sol}} H\left(\mathrm{~kJ} \mathrm{~mol}^{-1}\right)$ & $m\left(\mathrm{~mol} \mathrm{~kg}^{-1}\right)$ & $\Delta_{\mathrm{sol}} H\left(\mathrm{~kJ} \mathrm{~mol}^{-1}\right)$ & $m\left(\mathrm{~mol} \mathrm{~kg}^{-1}\right)$ & $\Delta_{\mathrm{sol}} H\left(\mathrm{~kJ} \mathrm{~mol}^{-1}\right)$ \\
\hline 0.0775 & -10.520 & 0.1004 & 2.850 & 0.0959 & -1.043 \\
\hline 0.1177 & -10.541 & 0.1197 & 2.851 & 0.1837 & -1.027 \\
\hline 0.1329 & -10.435 & 0.1910 & 2.952 & 0.2312 & -0.968 \\
\hline 0.1652 & -10.514 & 0.2123 & 2.904 & 0.2411 & -0.992 \\
\hline 0.2101 & -10.407 & 0.2256 & 2.947 & 0.2999 & -0.959 \\
\hline 0.2418 & -10.367 & 0.2395 & 2.991 & 0.3474 & -0.963 \\
\hline 0.2599 & -10.428 & 0.2507 & 2.999 & 0.3959 & -0.962 \\
\hline 0.2763 & -10.332 & 0.3435 & 2.995 & 0.4838 & -0.921 \\
\hline 0.3496 & -10.259 & 0.4249 & 2.977 & & \\
\hline 0.4132 & -10.237 & 0.4718 & 3.001 & & \\
\hline
\end{tabular}

A much deeper insight into solvation can be achieved by taking into account the intrinsic effect of the solute considered as a hard core particle on the solvent structure. To do this, the enthalpy of solvation can be considered as a sum of two terms: the enthalpy needed for creating a cavity in the solvent to hold the solute molecule, $\Delta_{\text {cav }} H$, and the enthalpy corresponding to the intermolecular forces up by the solute in solution, $\Delta_{\text {int }} H^{0}$. This term is related to $\Delta_{\text {solv }} H^{0}$ by the following expression [11]

$$
\Delta_{\text {solv }} H^{0}=\Delta_{\text {cav }} H^{0}+\Delta_{\text {int }} H^{0}+\alpha R T^{2}-R T,
$$

where $\alpha$ is the isobaric expansibility coefficient of the solvent and the last two terms of the right-hand side of the equation account for the solute standard states in gas and solution phases. $\Delta_{\text {cav }} H$ was calculated using
SPT. The results got for $\Delta_{\text {sol }} H^{0}, \Delta_{\text {solv }} H^{0}, \Delta_{\text {cav }} H$ and $\Delta_{\text {int }} H^{0}$ are given in Table 5 .

For the concentration range studied $\Delta_{\text {sol }} H$ dependence on concentration can be expressed by the following equation

$$
\Delta_{\text {sol }} H=\Delta_{\text {sol }} H^{0}+h_{\mathrm{xx}} m .
$$

The value for the pairwise coefficient, $h_{\mathrm{xx}}$, are evaluated by linear regression and can be found in Table 6 . The values obtained for $h_{\mathrm{xx}}$ can only be compared with those determined for the three isomeric butanediols in water by the dilution microcalorimetry technique [12]. They are of the same order of magnitude of those obtained in this study.

All uncertainties are expressed as twice the standard deviation.

Table 4

\begin{tabular}{|c|c|c|c|c|c|}
\hline \multicolumn{2}{|c|}{ 2,3-Butanediol/W } & \multicolumn{2}{|c|}{ 2,3-Butanediol/FMD } & \multicolumn{2}{|c|}{ 2,3-Butanediol/DMSO } \\
\hline$m\left(\mathrm{~mol} \mathrm{~kg}^{-1}\right)$ & $\Delta_{\mathrm{sol}} H\left(\mathrm{~kJ} \mathrm{~mol}^{-1}\right)$ & $m\left(\mathrm{~mol} \mathrm{~kg}^{-1}\right)$ & $\Delta_{\mathrm{sol}} H\left(\mathrm{~kJ} \mathrm{~mol}^{-1}\right)$ & $m\left(\mathrm{~mol} \mathrm{~kg}^{-1}\right)$ & $\Delta_{\mathrm{sol}} H\left(\mathrm{~kJ} \mathrm{~mol}^{-1}\right)$ \\
\hline 0.0691 & -14.568 & 0.0507 & 0.714 & 0.0617 & -1.011 \\
\hline 0.0861 & -14.477 & 0.1087 & 0.702 & 0.0745 & -0.868 \\
\hline 0.1061 & -14.435 & 0.1298 & 0.693 & 0.0791 & -0.938 \\
\hline 0.1318 & -14.638 & 0.1562 & 0.716 & 0.1018 & -0.910 \\
\hline 0.1578 & -14.673 & 0.1571 & 0.732 & 0.1222 & -0.938 \\
\hline 0.1964 & -14.734 & 0.2080 & 0.726 & 0.1388 & -0884 \\
\hline \multirow[t]{5}{*}{0.2600} & -14.722 & 0.2681 & 0.665 & 0.1677 & -0.900 \\
\hline & & 0.2941 & 0.664 & 0.1830 & -0.903 \\
\hline & & 0.3092 & 0.684 & 0.2206 & -0.906 \\
\hline & & & & 0.2294 & -0.911 \\
\hline & & & & 0.2574 & -0.891 \\
\hline
\end{tabular}

Enthalpies of solution of isomeric butanediols in different solvents at $298.15 \mathrm{~K}$ 
Table 5

Enthalpies of solution, enthalpies of solvation and values calculated for the enthalpies of cavity formation and solute/solvent interaction (in $\mathrm{kJ} \mathrm{mol}^{-1}$ ) for isomeric butanediols in several solvents at $298.15 \mathrm{~K}$

\begin{tabular}{|c|c|c|c|c|}
\hline Solute & $\Delta_{\text {sol }} H^{0}$ & $-\Delta_{\text {solv }} H^{0}$ & $\Delta_{\text {cav }} H$ & $-\Delta_{\text {int }} H^{0}$ \\
\hline \multicolumn{5}{|l|}{ Water } \\
\hline 1,2-Butanediol & $-11.71 \pm 0.08$ & $83.2 \pm 0.8$ & 7.01 & 87.9 \\
\hline 1,3-Butanediol & $-11.98 \pm 0.08$ & $86.4 \pm 1.0$ & 7.01 & 91.1 \\
\hline 1,4-Butanediol & $-10.61 \pm 0.07$ & $89.9 \pm 0.5$ & 7.01 & 94.6 \\
\hline 2,3-Butanediol & $-14.4 \pm 0.2$ & - & - & - \\
\hline \multicolumn{5}{|l|}{ Formamide } \\
\hline 1,2-Butanediol & $0.81 \pm 0.04$ & $70.7 \pm 0.8$ & 28.3 & 97.1 \\
\hline 1,3-Butanediol & $3.08 \pm 0.08$ & $71.4 \pm 1.0$ & 28.3 & 97.8 \\
\hline 1,4-Butanediol & $2.85 \pm 0.07$ & $76.4 \pm 0.5$ & 28.3 & 102.8 \\
\hline 2,3-Butanediol & $0.73 \pm 0.04$ & - & - & - \\
\hline \multicolumn{5}{|c|}{ Dimethylsulphoxide } \\
\hline 1,2-Butanediol & $-1.5 \pm 0.2$ & $73.0 \pm 0.8$ & 35.2 & 106.5 \\
\hline 1,3-Butanediol & $-0.089 \pm 0.009$ & $74.5 \pm 1.0$ & 35.2 & 108.0 \\
\hline 1,4-Butanediol & $-1.06 \pm 0.04$ & $80.4 \pm 0.5$ & 35.2 & 113.9 \\
\hline 2,3-Butanediol & $-0.95 \pm 0.06$ & - & - & - \\
\hline
\end{tabular}

\section{Discussion}

In former work [13] the authors presented arguments in favour of the interpretation of the thermodynamic data obtained for the solvation process based on $\Delta_{\text {int }} H^{0}$ rather than on $\Delta_{\text {solv }} H^{0}$. The reason for this lies in the significant contribution to solvation from the cavity term in polar solvents and the variations observed from one solvent to another. From this point of view, water is a special solvent as for as its $\Delta_{\mathrm{cav}} H$ much lower than the values found for organic solvents. The effect of the differences in $\Delta_{\text {cav }} H$ between solvents on $\Delta_{\text {solv }} H^{0}$ may lead to controversal molecular models of solvation [14-17] if they are based on this property. This conclusion is also true for the systems studied in the present work.

Comparison of the results obtained for $\Delta_{\text {solv }} H^{0}$ of a given isomer in the three solvents would lead to the conclusion that solute-solvent interactions are stron- ger in water than in the other liquids. This unexpected conclusion is modified when $\Delta_{\text {int }} H^{0}$ is considered. This property gives as an order for solvation in qualitative agreement with the dipole moment of the solvents, as would be expected. The order observed for solvation is, then, $\mathrm{W}<\mathrm{FMD}<\mathrm{DMSO}$.

Butanediol isomers give rise to different $\Delta_{\text {int }} H^{0}$ values. For any solvent this property becomes more negative as the distance between the hydroxyl groups of the solute increases. An increase of 3.2$3.5 \mathrm{~kJ} \mathrm{~mol}^{-1}$ is observed when one goes from 1,2to 1,3 - and from this to the 1,4-isomer in water. In the organic solvents about $1 \mathrm{~kJ} \mathrm{~mol}^{-1}$ is the difference between $\Delta_{\text {int }} \mathrm{mol}^{-1}$ for the 1,2- and 1,3-isomers, but an increase of $5 \mathrm{~kJ} \mathrm{~mol}^{-1}$ is observed on going from this last isomer to 1,4-butanediol.

It is worthwhile comparing the results obtained in this work for butanediols with those given for aliphatic open chain monofunctional alcohols in the same

Table 6

Solute-solute pairwise coefficient, $h_{\mathrm{xx}}$, for the different systems studied, at $298.15 \mathrm{~K}$

\begin{tabular}{llllc}
\hline Solvent & \multicolumn{2}{l}{ Solute $\left(h_{\mathrm{XX}}\left(\mathrm{kJ} \mathrm{kg} \mathrm{mol}^{-2}\right)\right)$} & & \\
\cline { 2 - 5 } & 1,2 -Butanediol & 1,3 -Butanediol & 1,4 -Butanediol & $-1 \pm 1$ \\
\hline $\mathrm{W}$ & $0.9 \pm 0.4$ & $0.8 \pm 0.4$ & $0.9 \pm 0.3$ & $-0.3 \pm 0.2$ \\
FMD & $0.1 \pm 0.1$ & $0.7 \pm 0.3$ & $0.4 \pm 0.2$ & $0.2 \pm 0.4$ \\
DMSO & $1.0 \pm 0.8$ & $0.06 \pm 0.04$ & $0.3 \pm 0.1$ & 0.4 \\
\hline
\end{tabular}


Table 7

Enthalpies of vaporisation of monoalcohols at $298.15 \mathrm{~K}$ [18]

\begin{tabular}{ll}
\hline Compound & $\Delta_{\text {vap }} H^{0}\left(\mathrm{~kJ} \mathrm{~mol}^{-1}\right)$ \\
\hline Methanol & 37.27 \\
Ethanol & 42.30 \\
$n$-Propanol & 47.32 \\
$n$-Butanol & 52.30 \\
$n$-Pentanol & 56.94 \\
\hline
\end{tabular}

solvents. We are not aware of any data published on dihydric alcohols but in water. From the results for the enthalpy of solution and for the enthalpy of vaporisation of monoalcohols published by other authors the enthalpy for solute-solvent interactions was calculated following the procedure described above. The data used in the calculation and the results obtained for $\Delta_{\text {solv }} H^{0}, \Delta_{\text {cav }} H$ and $\Delta_{\text {int }} H^{0}$ are given in Tables 7 and 8.

From the curves of $\Delta_{\text {int }} H^{0}$ against the number of carbon atoms of the solute molecule the following values for the contribution of $\mathrm{CH}_{2}$ and $\mathrm{OH}$ to the enthalpy are estimated: $\mathrm{CH}_{2}=-5.8,-7.5$ and $-7.6 \mathrm{~kJ} \mathrm{~mol}^{-1}$ in $\mathrm{W}, \mathrm{FMD}$ and DMSO, respectively; $\mathrm{OH}=-42.2,-43.2$ and $-49.5 \mathrm{~kJ} \mathrm{~mol}^{-1}$ in $\mathrm{W}, \mathrm{FMD}$ and DMSO, respectively.

\section{Table 8}

Enthalpies of solution, enthalpies of solvation and values calculated for the enthalpies of cavity formation and solute/solvent interaction (in $\mathrm{kJ} \mathrm{mol}^{-1}$ ) for monoalcohols in several solvents at $298.15 \mathrm{~K}$

\begin{tabular}{lclll}
\hline Solute & $\Delta_{\text {sol }} H^{0}$ & $-\Delta_{\text {sol }} H^{0}$ & $\Delta_{\text {cav }} H$ & $-\Delta_{\text {int }} H^{0}$ \\
\hline Water [19] & & & & \\
Methanol & -7.23 & 44.5 & 3.93 & 46.1 \\
Ethanol & -10.1 & 52.4 & 4.94 & 55.1 \\
$n$-Propanol & -10.2 & 57.5 & 5.83 & 61.0 \\
$n$-Butanol & -9.20 & 61.5 & 6.65 & 65.9 \\
$n$-Pentanol & -7.67 & 64.6 & 7.40 & 69.7 \\
Formamide [20] & & & & \\
Methanol & 0.837 & 36.4 & 15.7 & 50.4 \\
Ethanol & 2.13 & 40.2 & 20.0 & 58.3 \\
$n$-Propanol & 3.05 & 44.3 & 23.6 & 66.2 \\
$n$-Butanol & 3.81 & 48.5 & 26.9 & 73.5 \\
$n$-Pentanol & 4.48 & 52.5 & 30.0 & 80.5 \\
Dimethylsulphoxide $[19]$ & & & \\
Methanol & -1.42 & 38.7 & 20.0 & 57.0 \\
Ethanol & 1.21 & 41.1 & 25.0 & 64.4 \\
$n$-Propanol & 2.55 & 44.8 & 29.4 & 72.5 \\
$n$-Butanol & 3.97 & 48.3 & 33.4 & 79.9 \\
$n$-Pentanol & 5.40 & 51.5 & 37.2 & 87.0 \\
\hline
\end{tabular}

The values obtained for $\mathrm{CH}_{2}$ in different solvents are qualitatively ordered according to the polarizability of the solvent molecule and those for $\mathrm{OH}$ follow the order given by the electrical dipole moment. The value for $\Delta_{\mathrm{int}} H^{0}$ of butanediols estimated from the group contributions asserted above are significantly lower than those obtained from the experimental results. The difference may account for the mutual interference of the hydroxyl solvation spheres. As the distance between the $\mathrm{OH}$ groups increases $\Delta_{\mathrm{int}} H^{0}$ decreases but even for the 1,4-isomer the solvation sphere of each polar group is not accomplished.

Although this study is limited to dilute solutions, the variation of $\Delta_{\mathrm{sol}} H$ with concentration shows the existence of solute-solute intermolecular forces. The results obtained for $h_{\mathrm{xx}}$ cannot be correlated for the various systems, but a few general trends can be drawn. As the values obtained for this coefficient are positive, the interactions involve the solvent. Very likely the solute association, which will give rise to a negative enthalpy value, is accompanied by release of solvent molecules whose contribution overcomes the former effect. Water proves to be a stronger association promoter than the organic solvents.

\section{References}

[1] L.P. Kuhn, J. Am. Chem. Soc. 74 (1952) 2492.

[2] E. Fishman, T.L. Chen, Sprectrochim. Acta A 25 (1969) 1231.

[3] M. van Duin, J.M.A. Baas, B. van de Graaf, J. Org. Chem. 51 (1986) 1298.

[4] M. Trætteberg, K. Hedberg, J. Am. Chem. Soc. 116 (1994) 1382.

[5] H. Reiss, H.L. Frisch, J.L. Lebowitz, J. Chem. Phys. 31 (1959) 369.

[6] H. Reiss, R.V. Casberg, J. Chem. Phys. 61 (1974) 1107.

[7] J. Canotilho, F.S. Costa, A.T. Sousa, M.L.P. Leitão, J.S. Redinha, Thermochim. Acta 299 (1997) 1.

[8] N. Nichols, R. Sköld, C. Spink, I. Wadsö, J. Chem. Thermodyn. 8 (1976) 993.

[9] W.V. Steele, R.D. Chirico, S.E. Knipmeyer, A. Nguyen, J. Chem. Eng. Data 41 (1996) 1255.

[10] P. Knauth, R. Sabbah, Bull. Soc. Chim. Fr. 5 (1988) 834.

[11] R.A. Pierotti, Chem. Rev. 76 (1976) 717.

[12] G. Borghesani, R. Pedriali, F. Pulidori, I. Scaroni, J. Solut. Chem. 15 (1986) 397.

[13] F.S. Costa, M.E. Eusébio, J.S. Redinha, M.L.P. Leitão, J. Chem. Thermodynamics, in press.

[14] A. Holtzer, M.F. Emerson, J. Phys. Chem. 73 (1969) 26.

[15] R.D. Cramer III, J. Am. Chem. Soc. 99 (1977) 5408. 
[16] D.H. Wertz, J. Am. Chem. Soc. 102 (1980) 5316.

[17] N.A.M. Besseling, J. Lyklema, Pure Appl. Chem. 67 (1995) 881 .

[18] I. Wadsö, Acta Chem. Scand. 20 (1966) 544.
[19] C.V. Krishnan, H.L. Friedman, J. Phys. Chem. 73 (1969) 1572.

[20] C.V. Krishnan, H.L. Friedman, J. Phys. Chem. 75 (1971) 3598. 